\title{
Asma e ascaridíase: persiste a controvérsia
}

\author{
Asthma and ascariasis: ongoing controversy
}

\author{
Antonio José Ledo Alves da Cunha*
}

\begin{abstract}
A associação entre infestações helmínticas e doenças alérgicas permanece controversa na literatura ${ }^{1,2}$. $\mathrm{O}$ artigo de Silva et al. $^{3}$, publicado neste número do Jornal de Pediatria, vem colocar mais um ingrediente nesta questão polêmica; agora, porém, sob uma ótica nacional. Antes de entrar na discussão dos achados desta bem desenhada e conduzida investigação, algumas considerações preliminares são pertinentes. Inicialmente, é necessário destacar que a existência de uma possível associação entre a infestação por Ascaris lumbricoides e a ocorrência de asma na infância poderia ter importante impacto em saúde
\end{abstract} pública. Tendo a ascaridíase elevada prevalência em crianças brasileiras, em especial em regiões mais carentes, conforme demonstram Silva et al. em seu artigo, a diminuição desta parasitose poderia vir a contribuir para a diminuição da asma na

\section{Veja artigo relacionado na página 227}

alérgica com IgE específica para áscaris. Esse estudo tem especial interesse em função de seu delineamento visando estudar uma coorte de escolares, através de dois inquéritos com três anos de diferença, tendo sido possível observar escolares seronegativos para áscaris, no primeiro inquérito, que se tornaram seropositivos no segundo inquérito. Os autores observaram uma elevação da IgE total e específica para áscaris em crianças que se tornaram soropositivas, assim como um aumento de três vezes da sensibilização para dermatofagóides. Estes achados sugerem que o dermatofagóide possa estar implicado na relação áscaris e asma, colocando mais um fator na equação. Ademais, outro mecanismo que poderia explicar, ao menos em parte, uma possível associação entre asma e áscaris, e que não é aventado na literatura, tem a ver com a característica infância que, por sua vez, também tem elevada prevalência no Brasil. Isso traria não somente benefícios individuais para as crianças, mas também benefícios econômicos para as famílias e para o sistema de saúde. A temática trazida pelo artigo de Silva et al. ${ }^{3}$, portanto, vai além da identificação de fatores predisponentes, ou associados à asma, como uma maneira de melhor compreender a fisiopatologia da doença.

Nesta linha de raciocínio, torna-se também importante questionar se existe fundamento biológico plausível para explicar uma possível associação entre ascaridíase e asma. Alguns autores advogam que infecções gastrintestinais, incluindo as parasitárias, seriam fatores protetores à resposta imune, contribuindo para uma menor ocorrência de asma em populações infectadas ${ }^{4}$. Sabe-se entretanto, que as infecções helmínticas induzem a síntese de IgE através de uma estimulação policlonal dependente de IL4 ${ }^{5}$. Entretanto, esta relação está longe de explicar uma possível associação causal entre asma e infecção helmíntica. Em um estudo recente $^{5}$, os autores buscaram relacionar sensibilização

\footnotetext{
* Professor Adjunto, Dep. Pediatria e Diretor do Instituto de Puericultura e Pediatria Martagão Gesteira - Universidade Federal do Rio de Janeiro. Mestre em Pediatria (UFRJ) e em Saúde Pública (UNC). Doutor em Epidemiologia (UNC).
} migratória das larvas. A ocorrência de pneumonites e síndrome de Löffler pode ocasionar sibilos em crianças ${ }^{6}$. A passagem das larvas pelo pulmão poderia desencadear crises de asma e/ou favorecer a sensibilização de crianças infestadas.

Em relação ao artigo de Silva et al. ${ }^{3}$, merece destaque o fato de ter sido uma investigação planejada para estudar especificamente a associação entre asma e ascaridíase. Existem poucos estudos na literatura que analisam esta possível associação, e poucos dentre estes foram desenhados especificamente para esse fim. Porem, vários aspectos são comuns no artigo de Silva et al. ${ }^{3}$ e nos outros publicados sobre o tema em questão. Por exemplo, em se tratando de buscar evidências para uma possível associação causal entre asma e ascaridíase, em geral, não há compromisso por parte dos autores, o que é desejado e apreciado. As evidências que favorecem uma possível associação causal não são consistentes, não sendo possível, portanto, concluir se a ascaridíase favorece a asma, ou se asmáticos têm mais predisposição para ser infestados por áscaris. Esta observação é feita por Silva e col. ${ }^{3}$, de maneira muito pertinente, ao apontar a necessidade de estudos de coorte para que se possa compreender melhor o problema. Nesta linha, faz-se comentário a possível influência de possíveis erros sistemáticos $^{7}$ nos resultados e conclusões apresentadas. 
Com relação à amostra estudada, por exemplo, houve perda de $30 \%$ de crianças, que correspondem àquelas que não trouxeram o material para exame parasitológico. Como não se conhece as características deste grupo perdido, em especial com relação à infestação por áscaris, não sabemos que influência a exclusão deste grupo pode ter tido nos resultados observados. Se a maioria dos asmáticos $(60 \%$ dos que foram perdidos) estivesse infestada por áscaris, os resultados tenderiam, possivelmente, para uma associação positiva.

Outro possível erro sistemático ${ }^{7}$ pode ter ocorrido na classificação das crianças. O diagnóstico ou classificação, tanto de asma como de infestação por áscaris, é passível de erro, ou seja, não têm sensibilidade e especificidade de $100 \%$, como nenhum teste ou diagnóstico tem. Indivíduos classificados como asmáticos podem não sê-lo, ou viceversa, acontecendo o mesmo com relação à infestação por áscaris. Caso as proporções da ocorrência destes erros de classificação tenham sido semelhantes nos dois grupos analisados, o que chamamos de erro de classificação indiferenciado ${ }^{8}$, em se tratando de análise categórica onde somente duas categorias estão envolvidas ( para asma como para ascaridíase), os resultados tendem para uma atenuação de uma possível associação, caso esta exista. Esta atenuação é evidenciada na medida de associação, (que no caso poderia ter sido utilizada a razão de prevalência) e não no resultado do teste estatístico ou valor de "p". Ainda com relação a possíveis erros de classificação, deve-se considerar que apenas a infestação presente foi estudada. Casos de infestação no passado não foram levados em consideração.

Além do que foi comentado acima, sempre que se estuda a associação entre duas variáveis, no caso em questão asma e ascaridíase, deve-se levar em conta a possível influência de outras variáveis que podem estar confundindo os resultados encontrados, ou interagindo com uma das variáveis estudadas, modificando o efeito observado, tanto para mais, como para menos ${ }^{8}$. A influência de terceiras variáveis pode ser detectada através de análise estratificada e/ou multivariada dos resultados. Por exemplo, o fato de as crianças terem sido previamente sensibilizadas por dermatofagóides pode diminuir ou aumentar a força de uma possível associação entre asma e ascaridíase, caracterizando uma interação.

A influência de possíveis erros aleatórios ${ }^{7}$ nos resultados também merece atenção. Por exemplo, não houve cálculo amostral prévio, e não foi fornecida informação sobre o poder do estudo para detectar possíveis associações, neste caso, estatísticas. Assim, não é possível saber se as associações estatísticas não observadas não existiam, ou se o estudo não foi capaz de detectá-las. Podemos observar, na Tabela 2, que as razões de prevalência calculadas a partir dos dados fornecidos, embora fracas, tendem para uma possível associação. Por exemplo, a razão de prevalência foi de 1,33 (57,1\% dividido por 42,5\%) para a ocorrência de "sibilos uma vez" em crianças com áscaris. Com relação ainda a medidas, seria mais apropriada a utilização da razão de prevalência para estudar a associação em questão do que a estatística Kappa, uma vez que essa ultima é mais indicada para avaliar reprodutibilidade. Por exemplo, quando dois critérios diagnósticos distintos são utilizados por examinadores diferentes, para detectar uma mesma afecção (por exemplo, asma), utiliza-se a estatística Kappa para avaliar a concordância entre os examinadores.

Os comentários sobre a influência de possíveis erros sistemáticos e aleatórios nos resultados de Silva et al. ${ }^{3}$ não diminuem nem invalidam o estudo. Ao contrário, apontam, talvez em parte, as razões pelas quais a controvérsia persiste na literatura. Além disso, mostram também as dificuldades de se estudar o assunto, o que é preocupante, uma vez que os países menos desenvolvidos, com maior interesse no problema, em geral têm menos incentivos e, por conseguinte, mais dificuldades para conduzir investigações em saúde. Assim, além do mérito de trazer evidências nacionais sobre o assunto, Silva et al. ${ }^{3}$ denunciam uma situação grave na qual estão expostas crianças em Pedregal. Os autores concluem com muita pertinência, enfatizando a necessidade de medidas sanitárias urgentes para atacar o problema e a situação de saúde encontrada, bem como a necessidade de adoção de programas de promoção da saúde e prevenção de doenças, que devem ser de responsabilidade dos três níveis de governo.

\section{Referências bibliográficas}

1. Palmer LJ, Celedon JC, Weiss ST, Wang B, Fang Z, Xu X. Ascaris lumbricoides infection is associated with increased risk of childhood asthma and atopy in rural China. Am J Respir Crit Care Med 2002;165:1489-93.

2. de Almeida MM, Arede C, Marta CS, Pinto PL, Daniel I, Nogueira JA, et al. Atopy and enteroparasites. Allerg Immunol (Paris) 1998;30:291-4.

3. Silva MTN, Andrade J, Tavares-Neto J. Asma e ascaridíase em crianças de 2 a 10 anos de um bairro de periferia. J Pediatr (Rio J) 2003;79:227-32.

4. Correia JMM, Zuliani A. Imunidade relacionada à resposta a doença alérgica. J Pediatr (Rio J) 2001;77:441-6.

5. Dold S, Heinrich J, Wichmann HE, Wjst M. Ascaris-specific IgE and allergic sensitization in a cohort of school children in the former East Germany. J Allergy Clin Immunol 1998; 102:414-20.

6. Benenson AS. Manual para el control de las enfermedades transmisibles. $16^{\mathrm{a}}$ ed. Washington: Organización Panamericana de la Salud; 1997.

7. Fletcher RH, Fletcher SW, Wagner EH. Clinical epidemiology. The essentials. $3^{\text {a }}$ ed. Baltimore: Williams \& Wilkins; 1996.

8. Kleinbaun DG, Kupper LL, Morgenstern H. Epidemiologic research. Nova Iorque: Van Nostrand Reinhold; 1982. 